\title{
VORBEMERKUNG ZUR ÜBERSETZUNG
}

Um Joachim Latacz, den Begründer und Mitherausgeber des Basler Homerkommentars, zu entlasten, hat das Gesamtteam beschlossen, die Übersetzung beginnend mit diesem Gesang dem Mitherausgeber und Projektleiter anzuvertrauen. Die vorliegende Übersetzung stellt sich ganz in den Dienst des dazugehörigen Kommentars und seiner Nutzerinnen und Nutzer, indem sie möglichst alle dort vorgenommenen Präzisierungen, textkritischen Entscheidungen und Erklärungen abbildet.

Nach Wolfgang Schadewaldts Prinzip des »dokumentarischen« Übersetzens sollte eine textnahe, philologisch exakte und zugleich flüssig lesbare Übertragung in ein klares, zeitgemäßes Deutsch entstehen. Angestrebt ist, so genau wie möglich den Wortlaut und die Satzstruktur der Gedankenführung des Originals zu bewahren sowie die Gefühle und Motivation der Figuren, das Mündliche des Situativen und die pragmatischen Kommunikationsabsichten erlebbar werden zu lassen.

Im Italienischen gibt es das schöne Diktum: traduttore traditore. Es läßt erahnen, daß eine Übersetzung fast einem Verrat an der lebenden Dichtung der Ausgangssprache gleichkommt. Arthur Schopenhauer meint in seinen Parerga und Paralipomena: "Poesie ist ihrer Natur nach unübersetzbar.« Gerade im Falle Homers scheint die Skepsis angebracht zu sein. Wie soll man auch die homerische Formelhaftigkeit, die besondere Diktion, die Wiederholungen und die spezielle Atmosphäre übertragen? Eine »transponierende « Übersetzung in hohe, aber angestaubt wirkende poetische Formen der deutschen Klassik, die die Voß'schen, heute bisweilen komisch wirkenden Eigentümlichkeiten und Stilblüten weiterführt, wird hier vermieden. Dementsprechend sind formelhafte Ausdrücke nicht überall ganz konsequent identisch gesetzt, selten wird der Kontext aktiviert, vor allem wird bewußt auf eine metrisch gebundene Übertragung, sei es in Hexameter oder Iamben, verzichtet. Dafür entsteht ein sinnlich erfaßbarer Homer in einer mündlich geprägten Prosa in freien rhythmischen Formen. Das der Verbindung mit dem Kommentar geschuldete Opfer Joachim Latacz hat diesen Spagat noch zu meistern versucht - ist hoffentlich weder Verrat noch »Verkrüppelung« der Dichtung, sondern ein Versuch, die Dimensionen der Oralität und Performance in ihrer homerischen Kadenz erfahrbar werden zu lassen. 
Den beiden Autorinnen des Kommentars, Marina Coray und Martha Krieter, danke ich für das genaue Mitlesen, die produktive Kritik sowie das Abwägen, Austüfteln und Ausdiskutieren von Lösungen, bis die beiden Faszikel ganz ineinandergriffen.

Basel, im April 2021

Anton Bierl 